\title{
Metallomics
}

Cite this: Metallomics, 2014, 6, 2052

Received 30th April 2014, Accepted 24th June 2014

DOI: $10.1039 / c 4 m t 00124 a$

www.rsc.org/metallomics

\section{An iron stable isotope comparison between human erythrocytes and plasma $\dagger$}

\author{
Friedhelm von Blanckenburg, ${ }^{\star a}$ Marcus Oelze, ${ }^{a}$ Dietmar G. Schmid, ${ }^{b}$ \\ Kirsten van Zuilen, ${ }^{f}$ Hans-Peter Gschwind, ${ }^{b}$ Alan J. Slade, ${ }^{c}$ Sylvie Stitah, ${ }^{d}$ \\ Daniel Kaufmann ${ }^{\mathrm{e}}$ and Piet Swart ${ }^{\mathrm{b}}$
}

\begin{abstract}
We present precise iron stable isotope ratios measured by multicollector-ICP mass spectrometry (MC-ICP-MS) of human red blood cells (erythrocytes) and blood plasma from 12 healthy male adults taken during a clinical study. The accurate determination of stable isotope ratios in plasma first required substantial method development work, as minor iron amounts in plasma had to be separated from a large organic matrix prior to mass-spectrometric analysis to avoid spectroscopic interferences and shifts in the mass spectrometer's mass-bias. The ${ }^{56} \mathrm{Fe} /{ }^{54} \mathrm{Fe}$ ratio in erythrocytes, expressed as permil difference from the "IRMM-014" iron reference standard $\left(\delta^{56 / 54} \mathrm{Fe}\right)$, ranges from $-3.1 \%$ to $-2.2 \%$, a range typical for male Caucasian adults. The individual subject erythrocyte iron isotope composition can be regarded as uniform over the 21 days investigated, as variations $( \pm 0.059$ to $\pm 0.15 \%$ ) are mostly within the analytical precision of reference materials. In plasma, $\delta^{56 / 54} \mathrm{Fe}$ values measured in two different laboratories range from $-3.0 \%$ to $-2.0 \%$, and are on average $0.24 \%$ higher than those in erythrocytes. However, this difference is barely resolvable within one standard deviation of the differences $(0.22 \%)$. Taking into account the possible contamination due to hemolysis (iron concentrations are only 0.4 to $2 \mathrm{ppm}$ in plasma compared to approx. $480 \mathrm{ppm}$ in erythrocytes), we model the pure plasma $\delta^{56 / 54} \mathrm{Fe}$ to be on average $0.4 \%$ higher than that in erythrocytes. Hence, the plasma iron isotope signature lies between that of the liver and that of erythrocytes. This difference can be explained by redox processes involved during cycling of iron between transferrin and ferritin.
\end{abstract}

\section{Introduction}

The stable isotopes of iron bear potential to serve as biomarkers for metabolic processes in humans. ${ }^{1}$ The introduction of multicollector inductively-coupled-mass spectrometers (MC-ICP-MS) about 15 years ago (see ref. 2 for a review) has enabled disclosing this potentially rich reservoir of information on nutrient uptake paths, processes, and efficiencies. ${ }^{3}$ Concerning the stable isotopes of iron, it is now well-established that the human blood and muscle tissue are enriched in the stable

\footnotetext{
${ }^{a}$ GFZ German Research Center for Geosciences, Potsdam, Germany. E-mail: fvb@gfz-potsdam.de

${ }^{b}$ NIBR/DMPK, Novartis Pharma AG, Basel, Switzerland

${ }^{c}$ NIBR/Translational Medicine, Novartis Corporation, East Hanover, USA

${ }^{d}$ Clinical Science and Innovation, Novartis Pharma AG, Basel, Switzerland

${ }^{e}$ Chemical and Analytical Development, Novartis Pharma AG, Basel, Switzerland

${ }^{f}$ Institute of Geological Sciences, University of Berne, Switzerland

$\dagger$ Electronic supplementary information (ESI) available: Supplement 1: Fe isotope delta-delta graphs of reference materials and samples. Supplement 2: compilation of internal laboratory reference iron standards. Supplement 3: measured Fe concentration and isotope data on blood. Supplement 4: measured Fe concentration and isotope data on blood plasma. Supplement 5: SBR759 measured iron isotope composition. See DOI: $10.1039 / \mathrm{c} 4 \mathrm{mt} 00124 \mathrm{a}$
}

isotope of ${ }^{54} \mathrm{Fe}$ by one to two permil [\%o] over ${ }^{56} \mathrm{Fe}$ when compared to the human diet. ${ }^{1,3,4}$ However, the light iron isotopes are distributed unevenly - blood was found to contain the lightest composition, whereas the liver was less enriched in ${ }^{54} \mathrm{Fe} .{ }^{1}$ This picture was confirmed by a pig model study ${ }^{5}$ and by observations in mice and sheep. ${ }^{6}$

These observations raise mechanistic questions about the observed tissue dependent iron isotope fractionation. Massdependent stable isotope fractionation may occur during transport of ions or molecules, or during formation or breaking of chemical bonds. Nevertheless, isotope fractionation will only become detectable if the atomic species, differing in their isotope ratios, are separated in physically distinct compartments. Following these considerations it has been suggested that the uptake of dissolved iron via the intestinal mucosa is the most likely site of fractionation. In the case of intestinal iron absorption, the transfer from the luminal side to the blood plasma is incomplete; on average only $1 \mathrm{mg}$ of dietary supply of approx. 10 to $15 \mathrm{mg}$ of ingested iron is absorbed. ${ }^{1,7}$ In addition, the uptake of elemental iron requires the reduction of dietary $\mathrm{Fe}(\mathrm{III})$ to $\mathrm{Fe}(\mathrm{II})$ that is transported by a divalent metal transporter (DMT-1) via an intestinal ferric reductase (Dcytb). ${ }^{8}$ The redox 
processes involve an equilibrium isotope fractionation shifting the ${ }^{56} \mathrm{Fe} /{ }^{54} \mathrm{Fe}$ ratio by approx. 3\% to low values in the ferrous iron as shown by experimental determination ${ }^{9}$ and $a b$ initio calculation of isotope fractionation factors. ${ }^{10}$ Within the intestinal mucosa, a similar, oxidative process via the ferroxidase hephaestin is required to convert the absorbed $\mathrm{Fe}$ (II) back to $\mathrm{Fe}$ (III) for further distribution via transferrin. ${ }^{8}$

In this regard, the protein transferrin, bearing two iron binding sites, and contained mostly in blood plasma, is a key player. ${ }^{11}$ After intestinal uptake, freshly absorbed iron is loaded onto transferrin and transported within the blood plasma to various organs and tissues. Although only about $0.1 \%$ of total body iron ( $3 \mathrm{mg}$ ) is bound to transferrin, the daily turnover is significant, where 20 to $25 \mathrm{mg}$ are transported through the blood plasma each day. ${ }^{7 a}$ Most iron is transported into the red bone marrow for synthesis of hemoglobin and erythrocytes. As noted previously, the internal distribution of iron within the human body is subject to further isotopic fractionation. ${ }^{1,5}$ One possible explanation for the different isotopic compositions of these iron storage compartments is isotope fractionation during transport or during iron loading and unloading from transferrin. The same holds for iron release from transferrin. Upon binding to the transferrin receptor, the transferrin-receptor complex is internalized via endocytosis. Should isotope fractionation during transferrin loading and release be zero, then the iron composition of erythrocytes should resemble that of plasma. However, transferrin also transports a substantial amount of iron from other storage compartments like the liver. Thus, another potential process entailing fractionation is during iron storage and release from various tissue depots. Iron is stored as a stable ferrihydrate complex in ferritin where Fe(II) is oxidized to Fe(III) by ferroxidase in the ferritin complex. ${ }^{12}$ It has been shown in humans that the liver contains iron of which the ${ }^{56} \mathrm{Fe} /{ }^{54} \mathrm{Fe}$ ratio is higher than that of erythrocytes. ${ }^{1,5}$ If during release from the liver this heavy iron is not fractionated towards the erythrocytes' ratio, then transferrin should contain iron comprising a mixture of that delivered during hemoglobin synthesis with that delivered from the liver. Hence, the transferrin's isotope composition should lie between that of the liver and that of erythrocytes. To date, only one study has reported the iron composition of human blood plasma and found it to be enriched in ${ }^{56} \mathrm{Fe}$ over ${ }^{54} \mathrm{Fe}$ relative to blood, and hence being of composition closer to liver iron. ${ }^{13}$

In this study we test these hypotheses by presenting precise iron stable isotope ratios measured in human erythrocytes and plasma samples. Blood was sampled over a period of 21 days from 12 healthy male adults. The study was performed within the context of a ferrokinetics and uptake study of iron following administration of oral doses of the compound SBR759, labeled with the stable isotope ${ }^{58} \mathrm{Fe}$. The results of the iron uptake study are presented in a companion paper. ${ }^{14} \mathrm{~A}$ challenge for such an investigation is the determination of accurate, stable iron isotope ratios in plasma. Plasma iron concentrations are approx. 0.4 to $2 \mathrm{ppm}$ compared to that of erythrocytes which can be greater than $400 \mathrm{ppm}$. Hence, a large organic matrix has to be separated prior to mass-spectrometric analysis to avoid spectroscopic interferences and shifts in the mass-bias introduced during measurements by impurities contained in the samples. ${ }^{15}$ Presenting suitable analytical protocols is therefore the first aim of this study.

\section{Subjects and study design}

Our investigation is part of an open-label study that was undertaken to determine the ferrokinetics and uptake of iron in healthy volunteers following administration of oral doses of SBR759, an investigational drug being developed for the treatment of hyperphosphatemia in patients with chronic kidney disease, labeled with a stable ${ }^{58} \mathrm{Fe}$ isotope, (for additional information, see ref. 14). The clinical part of the study was performed at Covance Clinical Research Unit AG (former Swiss Pharma Contract Ltd), Allschwil, Switzerland. This study was approved by the local ethics committee and was conducted in accordance with the declaration of Helsinki (1964 and subsequent revisions) and International Conference on Harmonization-Good Clinical Practice guidelines. All subjects gave written informed consent before participating in the study.

\section{Subjects}

A total of 12, iron replete (i.e., nonanemic), healthy, nonsmoking, male volunteers between 18 and 45 years of age were recruited. This subject population was selected because of their propensity for iron absorption, noting similarities in absorption of therapeutic iron salts by patients with chronic kidney disease (CKD) on hemodialysis. Subjects with (i) hematocrit $<41 \%$, (ii) hemoglobin $<13.8$ or $>17.2 \mathrm{~g} \mathrm{dL}^{-1}$, (iii) serum ferritin $<20$ or $>320 \mathrm{ng} \mathrm{mL} \mathrm{mL}^{-1}$, (iv) transferrin saturation $<20 \%$, (v) reticulocyte count $>1.5 \%$ or platelets $<100000 \mu \mathrm{L}^{-1}$, and (vi) history of anemia, hemochromatosis or other dyscrasia(s), e.g. thalassemia, myelodysplastic syndrome, etc., were excluded from the study. The mean age was $34.2 \pm 8.8$ years, the mean height was $177 \pm 7.0 \mathrm{~cm}$, the mean body weight was $80.1 \pm 15.1 \mathrm{~kg}$, and the mean body mass index (BMI) was $25.3 \pm$ $3.8 \mathrm{~kg} \mathrm{~m}^{-2}$. Each subject participated in a 21-day screening period (Day-2 to Day-21), a baseline period (Day-1), and a 12 hour dosing period (Day 1, three administrations of $4 \mathrm{~g}$ of $\left[{ }^{58} \mathrm{Fe}\right] \mathrm{SBR} 759$ each) followed by a 3 week ambulatory period and study completion on Day 21. Subjects received a total daily dose of $12 \mathrm{~g}$ (divided into $3 \times 4 \mathrm{~g})($ mean $\pm \mathrm{SD}, n=12: 12.47 \pm 0.017 \mathrm{~g})$ of $\left[{ }^{58} \mathrm{Fe}\right] \mathrm{SBR} 759$.

\section{Sample collection}

Serial blood samples were collected at $0 \mathrm{~h}$ (pre-dose; baseline), 6, 12, 16, 22 (Day 1), 26, 34 (Day 2), 106 (Day 5), 250 (Day 11), 322 (Day 14), and $490 \mathrm{~h}$ (Day 21) post first dose. In order to avoid hemolysis during Day 1 and Day 2 when several blood withdrawals took place, blood samples were collected by inserting a plastic cannula fixed at the forearm. For blood sampling at Days $5,11,14$ and 21, a metallic needle (venipuncture) was used for individual samplings. Blood was collected in special $7.5 \mathrm{~mL}$ blood collection tubes for metal analysis by slow aspiration. The tubes, which resemble a single-use syringe, contained a small and specified amount of metal impurities $(<50 \mathrm{ng}$ iron/tube; S-Monovette ${ }^{\circledR}$ for metal analysis; model\# 01.1604.400, Sarstedt, Germany). These tubes also contained about $4-7 \mu \mathrm{L}$ of a lithium 
heparin solution corresponding to about $0.1 \%$ of the final blood sample volume. After blood collection the tubes were inverted gently to mix the contents. Immediately after collection, five aliquots of whole blood were exactly weighed into pre-labeled polypropylene cryotubes and stored at $\leq-20{ }^{\circ} \mathrm{C}$.

Plasma was obtained from heparinized blood by centrifugation at $2000 \times g$, at $4{ }^{\circ} \mathrm{C}$ for $10 \mathrm{~min}$. Plasma was recovered into pre-weighed tubes (Monovettes for metal analysis, Sarstedt) and stored at $\leq-20{ }^{\circ} \mathrm{C}$. Plasma samples which displayed visible signs of hemolysis were excluded from data analysis. Plasma was prepared from blood at $0 \mathrm{~h}$ (pre-dose), 6, 12, 16, 22 and $26 \mathrm{~h}$ post first dose.

After sample collection, erythrocyte and plasma samples were frozen immediately and stored at $\leq-20{ }^{\circ} \mathrm{C}$ until and after analysis in the analytical laboratories. Samples were shipped to analytical laboratories under dry ice to keep them frozen.

\section{Materials and methods}

Iron stable isotope measurements by MC-ICP-MS require separation of pure iron from the samples' matrix. The separation techniques used as well as the mass-spectrometric analysis have been described in detail ${ }^{15}$ and are not repeated here. However, the decomposition of blood and plasma samples requires microwave-aided treatment. The required protocols not described in ref. 15 are reported here in more detail.

\section{Microwave treatment - blood samples}

After thawing, each blood sample was shaken gently to ensure homogeneity. A volume of approx. $100 \mu \mathrm{L}$ was pipetted into preweighed microwave treatment vessels. After adding $5 \mathrm{~mL}$ of $5 \mathrm{M}$ $\mathrm{HNO}_{3}$ and $1 \mathrm{~mL}$ of $\mathrm{H}_{2} \mathrm{O}_{2}(30 \% \mathrm{w} / \mathrm{w})$, microwave treatment was performed on a CEM Mars 5 microwave system (CEM GmbH, Kamp-Lintfort, Germany) at 1200 Watts, at $200{ }^{\circ} \mathrm{C}$ for 2 hours. Only after complete sample processing the resulting clear solutions were transferred into Savillex ${ }^{\circledR}$ Teflon beakers and evaporated to dryness. The residues were re-dissolved in $3 \mathrm{~mL}$ of $6 \mathrm{M}$ hydrochloric acid and split gravimetrically into two aliquots. One of these aliquots was used for determining the total iron content in the whole blood sample by using a calibrated inductively-coupled optical emission spectroscopy (ICP-OES) system (Varian Vista PRO CCD Simultaneous at the Institute for Mineralogy from the Leibniz University Hannover, Germany). In addition, major elements such as nickel that potentially interferes with the MC-ICP-MS measurements were quantified by ICP-OES.

\section{Microwave treatment - plasma samples}

As plasma sample amounts (approx. $15 \mathrm{~mL}$ ) were too large to be decomposed in a single microwave treatment vessel, each sample was split into 2 aliquots. To each of these $6 \mathrm{~mL}$ of $15 \mathrm{M} \mathrm{HNO}_{3}$ and, with a lag time of $10 \mathrm{~min}, 1 \mathrm{~mL}$ of $\mathrm{H}_{2} \mathrm{O}_{2}(30 \% \mathrm{w} / \mathrm{w})$ was added. The solutions were treated with the microwave system (heating up to $200{ }^{\circ} \mathrm{C}$ for $25 \mathrm{~min}$; kept at $200{ }^{\circ} \mathrm{C}$ for $50 \mathrm{~min}$ ). After cooling down for $40 \mathrm{~min}$, samples were transferred into $90 \mathrm{~mL}$
Savillex beakers. The samples were dried and re-dissolved in $5 \mathrm{~mL}$ of $6 \mathrm{M}$ hydrochloric acid. At this stage an insoluble solid residue precipitated. The residual solid phase was removed by centrifugation.

To test whether the insoluble residues were free of iron, a standard addition experiment was conducted on a plasma test sample. This sample was split into two aliquots before freezedrying. The first aliquot was then split into 6 sub-splits. To each of these a known amount of CertiPUR ${ }^{\circledR}$ iron standard was added in increasing volumes. To the first aliquot, the additions were made before freeze-drying. To the second aliquot, the additions were made after dissolution and separation of the insoluble residue by centrifugation. The iron amounts found in both experiments were roughly identical within analytical error, which ranged from 1 to $7 \%$. Hence no iron from the original plasma or from the additions was lost into the precipitate. Given that this step did not result in loss of iron, all plasma concentration measurements were performed on a $300 \mu \mathrm{L}$ aliquot taken from the $6 \mathrm{M}$ hydrochloric acid solution.

\section{Iron separation}

Sample aliquots, re-dissolved in $6 \mathrm{M}$ hydrochloric acid, were loaded onto an ion exchange column containing $1 \mathrm{~mL}$ of Dowex AG $1 \times 8,200-400$ mesh anion exchange resin (Dow Water and Process Solutions). The amount of iron loaded onto the Eichrom polypropylene columns (Eichrom Europe Laboratories, Bruz, France) was precisely determined by ICP-OES so that the exchange capacity of columns was not exceeded. Iron was separated from the bulk of the matrix following ref. 15 .

For samples containing high initial amounts of transition metals or organic matrices, iron separated by anion exchange chromatography may not be entirely matrix-free and requires further purification. Therefore, all samples were neutralised with ammonia and subjected to a precipitation step. ${ }^{15}$ For plasma samples which in general contain much less iron when compared to blood, a normal precipitation step ${ }^{15,16}$ could not be applied. Instead, plasma samples were co-precipitated after chromatographic separation by adding $1 \mathrm{~mL}$ of a $1000 \mathrm{ppm}$ aluminum solution into $0.3 \mathrm{M} \mathrm{HNO}_{3}$, which was first precleaned by anion exchange chromatography to remove traces of iron. The co-precipitation was achieved by adding $\mathrm{NH}_{4} \mathrm{OH}$ to the samples. To achieve maximum iron yields, the solutions were allowed to equilibrate for 1 hour before centrifugation. The supernatants were removed and the precipitates were washed 2-times with Milli-Q $\mathrm{H}_{2} \mathrm{O}$, followed again by centrifugation and finally re-dissolved in $1 \mathrm{~mL}$ of $6 \mathrm{M}$ hydrochloric acid. To remove the aluminum, a second anion exchange chromatography was necessary, which followed the same procedure as the first one at the beginning of the iron separation scheme. The eluents were then dried and dissolved in $5 \mathrm{~mL}$ of $0.3 \mathrm{M} \mathrm{HNO}_{3}$.

\section{MC-ICP-MS}

Several analytical protocols for the precise determination of iron stable isotopes are published. ${ }^{15-17}$ In this study we follow the method described in ref. 15 with adaptations. The isotope ratios were determined on a Thermo Finnigan "Neptune" 
Multicollector ICP-MS at the Institute for Mineralogy from the Leibniz University Hannover, Germany. ${ }^{18}$ Sample solutions were nebulised and introduced using the Thermo Finnigan stable introduction system (SIS). This system consists of a combined cyclonic and Scott-type spray chamber. The baseline measurements prior to each analyses were performed by taking a deflected baseline at the start of a sequence. An "on-peak zero" measurement was done before each sample and a standard measurement was done on $0.3 \mathrm{M} \mathrm{HNO}_{3}$ to subtract the background signal introduced by the interaction of the sample and the ion beam with parts of the inlet system and the mass spectrometer from measured standard and sample signals.

Whereas argides can be resolved from each corresponding iron isotope due to the high mass resolving power of the MC-ICPMS, potential isobaric interferences of ${ }^{54} \mathrm{Cr}^{+}$and ${ }^{58} \mathrm{Ni}^{+}$on ${ }^{54} \mathrm{Fe}^{+}$and ${ }^{58} \mathrm{Fe}^{+}$, respectively, were minimised by removal of chromium and nickel using anion exchange chromatography. The purity of the fractions after anion exchange chromatography was monitored by ICP-OES. To correct for minor residual interferences, the isotopes ${ }^{52} \mathrm{Cr}$ and ${ }^{60} \mathrm{Ni}$ were measured in parallel with ${ }^{54} \mathrm{Fe},{ }^{56} \mathrm{Fe},{ }^{57} \mathrm{Fe}$ and ${ }^{58} \mathrm{Fe}$. The interference correction for ${ }^{54} \mathrm{Cr}$ on ${ }^{54} \mathrm{Fe}$ and ${ }^{58} \mathrm{Ni}$ on ${ }^{58} \mathrm{Fe}$ was performed according to ref 15 . Briefly, the amount of ${ }^{54} \mathrm{Cr}$ was calculated from the intensity of ${ }^{52} \mathrm{Cr}$ measured simultaneously and from the average natural ${ }^{54} \mathrm{Cr} /{ }^{52} \mathrm{Cr}$ ratio. The amount of interfering ${ }^{58} \mathrm{Ni}$ was calculated from the average natural ${ }^{60} \mathrm{Ni} /{ }^{58} \mathrm{Ni}$ ratio. An instrumental mass discrimination factor was applied to ${ }^{52} \mathrm{Cr}$ and ${ }^{58} \mathrm{Ni}$ intensities, respectively, which was determined from the measured ${ }^{57} \mathrm{Fe} /{ }^{56} \mathrm{Fe}$ ratio by applying the exponential mass bias law.

Instrumental mass discrimination induced by the incomplete removal of the sample matrix or non-reproducible mass-spectrometric run conditions potentially introduced a substantial bias into the resulting isotope ratio measurements. As iron concentrations in blood plasma are low, and a large organic matrix is present, these measurements are particularly prone to such bias. For this reason the measurement of 18 separated plasma iron samples was repeated on a similar instrument (Thermo Neptune Plus Multicollector ICP-MS) based at the GeoForschungsZentrum Potsdam. For these measurements, ESI Apex-Q desolvating apparatus using a low flow (aspiration rate of $100 \mu \mathrm{L} \mathrm{m^{-1 }}$ ) PFA self-aspirating nebuliser was used. The ESI Apex-Q apparatus consists of a heated cyclonic glass spray chamber coupled with a Peltier element-cooled glass spiral condenser. The mass spectrometer's interface was equipped with Thermo "Jet" cones. This instrumental setup, which differs considerably from that used at the University of Hannover, would detect a potential matrix-induced mass bias in the form of non-reproducible isotope ratios.

\section{Iron standards for controlling MC-ICP-MS measurements}

A commercially available "IRMM-014" iron bracketing reference standard was used (from EU Institute for Reference Materials and Measurements, Geel, Belgium). ${ }^{19}$ Additionally, the "JM" internal iron laboratory standard (Fe Puratronic wire, 99.998\% purity, lot NM36883; Johnson \& Matthey, London, UK) was used for optimizing instrumental run conditions and assessing instrumental reproducibility. The differences in Fe isotope composition between "JM" and "IRMM-014" Fe solutions have been reported. ${ }^{15,18}$ In this study, additionally a second internal laboratory standard "HanFe" was measured against the "IRMM-014" iron standard. Iron isotope data for samples is only accepted if the iron isotope composition of a known iron standard measured repeatedly in the same analysis session is within the uncertainty limits. ${ }^{15}$ To ensure this in each session, three to six samples of the internal "JM" and the new internal "HanFe" iron reference standards were measured in most sessions. For the "JM" reference, the mean values obtained in 96 measurements over 18 sessions agreed with those given in ref 15 and "HanFe" yielded $\delta^{56} \mathrm{Fe} /{ }^{54} \mathrm{Fe}$ values within the range of 0.28 to $0.30 \%$ as measured now by four different laboratories ${ }^{20}$ (ESI, $\dagger$ Table S1).

\section{Iron isotope fractionation due to incomplete recovery}

Quantitative recovery and removal of matrix elements during iron separation and precipitation were controlled by iron concentration measurements with small aliquots of the samples before and after each step by ICP-OES. This check is important because non-quantitative recovery could result in artificial isotope fractionation. ${ }^{21}$ A $90 \%$ recovery limit for iron recovery after ion exchange separation was set as the acceptance criterion. The total iron recovery was monitored by ICP-OES. Only in four blood samples the iron recovery was lower than $90 \%$. One sample was partially lost and did not allow calculating the iron recovery. Only in two plasma samples, the iron recovery was lower than $90 \%$. One sample was partially lost and could not be analyzed. The total procedural iron blanks were measured with mostly less than $60 \mathrm{ng}$. This was less than 1\% of the processed iron (with a minimum measurable Fe content of $6 \mu \mathrm{g}$ ) and was considered to be insignificant.

\section{Reporting of isotope ratios}

All isotope ratios were reported in permil deviations from the "IRMM-014" reference material:

$$
\frac{\delta^{56} \mathrm{Fe}}{\% 0}=\left(\frac{{ }^{56} \mathrm{Fe} /{ }^{54} \mathrm{Fe}_{\text {sample }}}{{ }^{56} \mathrm{Fe} /{ }^{54} \mathrm{Fe}_{\text {IRMM-014 }}}-1\right) \times 1000
$$

A similar equation is used for $\delta^{57} \mathrm{Fe}$ and $\delta^{58} \mathrm{Fe}$ when ${ }^{56} \mathrm{Fe}$ is replaced by ${ }^{57} \mathrm{Fe}$ or ${ }^{58} \mathrm{Fe}$, respectively.

\section{Results}

\section{MC-ICP-MS method validation and assessment}

Iron isotope specificity and isobaric interferences. To avoid artefacts introduced by high chromium or nickel corrections, Fe isotope analyses with ${ }^{54} \mathrm{Cr} /{ }^{54} \mathrm{Fe}>0.1 \%$ shall be rejected from the data set as well as $\delta^{58} \mathrm{Fe}$ values of samples with ${ }^{58} \mathrm{Ni} /{ }^{58} \mathrm{Fe}>10 \%$. ${ }^{15}$ The interferences on ${ }^{58} \mathrm{Fe}$ are reported in some detail here as they are important for the companion paper. ${ }^{14}$ In this study, the ${ }^{54} \mathrm{Cr} /{ }^{54} \mathrm{Fe}$ ratios in blood ranged from $0.0018 \%$ o to $0.029 \%$ and the ${ }^{58} \mathrm{Ni} /{ }^{58} \mathrm{Fe}$ ratios ranged from zero to $6.20 \%$. The ${ }^{54} \mathrm{Cr} /{ }^{54} \mathrm{Fe}$ ratios in plasma ranged from $0.022 \%$ o to $0.128 \%$ and the ${ }^{58} \mathrm{Ni} /{ }^{58} \mathrm{Fe}$ ratios ranged from zero to 
9.09\% . Two blood samples displayed high ${ }^{58} \mathrm{Ni} /{ }^{58} \mathrm{Fe}$ ratios of $18.1 \%$, $34.7 \%$, and one plasma sample showed a ${ }^{58} \mathrm{Ni} /{ }^{58} \mathrm{Fe}$ ratio of $12.9 \%$. Since their measured $\delta^{58} \mathrm{Fe}$ values were sufficiently high after absorption of SBR759, these samples were therefore nonetheless included in the iron absorption calculation. ${ }^{14}$

Another test for the presence of isobaric interferences is the use of three isotope plots, where offsets from the predicted mass-dependent fractionation curve indicate the presence of isobaric interferences. The delta/delta graphs of normalised iron isotope ratios $\left(\delta^{57} \mathrm{Fe} /{ }^{54} \mathrm{Fe}\right.$ versus $\delta^{56} \mathrm{Fe} /{ }^{54} \mathrm{Fe}$ and $\delta^{58} \mathrm{Fe} /{ }^{54} \mathrm{Fe}$ versus $\delta^{56} \mathrm{Fe} /{ }^{54} \mathrm{Fe}$ ) of the "JM" and "HanFe" iron standards are depicted in Fig. S1a-d (ESI $\dagger$ ) and of baseline blood and plasma samples in Fig. S1e-h (ESI $\dagger$ ). All standard and sample results plot onto the mass-dependent isotope fractionation line, which indicates measurements that were free of spectral interferences. Blood and plasma samples post first dose containing absorbed $\left.{ }^{58} \mathrm{Fe}\right]$ SBR759-related iron might contain a relatively higher fraction of ${ }^{57} \mathrm{Fe}$ (i.e. "impurity" in the ${ }^{58} \mathrm{Fe}$ label), as compared to its natural abundance. The isotopic composition of $\left[{ }^{58} \mathrm{Fe}\right]$ SBR759 relative to the international "IRMM-014" reference material was determined to be $5.706 \%{ }^{54} \mathrm{Fe}, 89.552 \%{ }^{56} \mathrm{Fe}, 2.077 \%{ }^{57} \mathrm{Fe}$, and $2.665 \%{ }^{58} \mathrm{Fe},{ }^{14}$ which compares to $5.845 \%{ }^{54} \mathrm{Fe}, 91.754 \%{ }^{56} \mathrm{Fe}, 2.12 \%{ }^{57} \mathrm{Fe}$, and $0.281 \%{ }^{58} \mathrm{Fe}$ for the reference material "IRMM-014". ${ }^{19}$ Hence in this study $\delta^{57} \mathrm{Fe}$ and $\delta^{58} \mathrm{Fe}$ for post first dose samples are not used.

For plasma samples, we observed higher ${ }^{52} \mathrm{Cr}$ levels than for either blood samples or the standard materials. We tested whether this increase was due to unresolved ${ }^{40} \mathrm{Ar}^{12} \mathrm{C}$ interferences on mass 52 . In that case the ${ }^{54} \mathrm{Fe}$ intensities would be over-corrected for ${ }^{54} \mathrm{Cr}$. We plotted the $\delta^{57} \mathrm{Fe} /{ }^{56} \mathrm{Fe}$ ratio against $\delta^{56} \mathrm{Fe} /{ }^{54} \mathrm{Fe}$ of plasma baseline samples (Fig. 1). The ${ }^{57} \mathrm{Fe} /{ }^{56} \mathrm{Fe}$ ratio is not subject to a $\mathrm{Cr}$ interference correction. The fact that all data plot on the mass-dependent fractionation curve, regardless of whether they have been corrected for $\mathrm{Cr}$ interferences, shows that $\mathrm{Cr}$ corrections did not introduce a bias resulting from excessive ${ }^{54} \mathrm{Fe}$ corrections.

Instrumental iron isotope mass bias drift. The blood and plasma samples were also monitored for their instrumental mass bias drift during measurements. Samples for which the two directly bracketing standard measurements exceed an instrumental mass bias drift of $\pm 200 \mathrm{ppm}$ on the ${ }^{56} \mathrm{Fe} /{ }^{54} \mathrm{Fe}$ ratio were set as a rejection criterion. ${ }^{15}$ As plasma samples were difficult to measure due to their complex matrix, we relaxed this criterion slightly to $220 \mathrm{ppm}$. The mass bias drift for blood samples ranged between $-202 \mathrm{ppm}$ and $162 \mathrm{ppm}$ (mean $\pm \mathrm{SD}$ of the absolute values: $44.9 \pm 30.0 \mathrm{ppm}(n=181))$. Only one sample exceeded this bias shift slightly (202 ppm) and was rejected. The drift in mass bias on the ${ }^{56} \mathrm{Fe} /{ }^{54} \mathrm{Fe}$ ratios measured in plasma samples ranged from $-476 \mathrm{ppm}$ to $321 \mathrm{ppm}$ (mean $\pm \mathrm{SD}$ of the absolute values: $96.8 \pm 96.6 \mathrm{ppm}, n=71)$.

\section{Long term iron concentration and isotope ratio stability of blood and plasma samples}

Mean subject iron concentrations in erythrocytes (as measured in whole blood samples) ranged between 428 and 497 ppm (Table 1); mean plasma iron concentrations varied between 0.59 and $1.2 \mathrm{ppm}$ (Table 1). Iron concentrations in erythrocyte

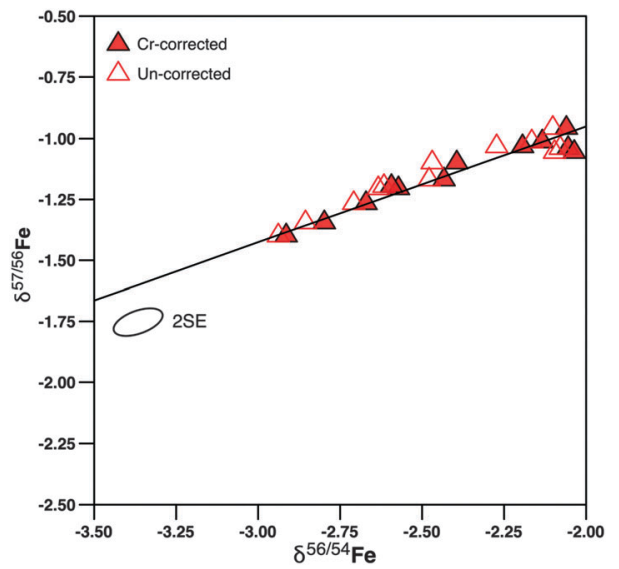

Fig. $1 \delta^{57} \mathrm{Fe} /{ }^{56} \mathrm{Fe}$ versus $\delta^{56} \mathrm{Fe} /{ }^{54} \mathrm{Fe}$ diagram as test for excessive ${ }^{54} \mathrm{Cr}$ interference due to the presence of an ${ }^{40} \mathrm{Ar}^{12} \mathrm{C}$ interference on the monitor isotope ${ }^{52} \mathrm{Cr}$ in plasma baseline samples (taken before administration of SBR759 to ensure the absence of a ${ }^{57} \mathrm{Fe}$ contribution from the spike). The ${ }^{57} \mathrm{Fe} /{ }^{56} \mathrm{Fe}$ ratio is not subject to a $\mathrm{Cr}$ interference correction. Open symbols: $\delta^{56} \mathrm{Fe}$ not corrected for " $\mathrm{Cr}$ " interference; closed symbols: $\delta^{56} \mathrm{Fe}$ ratios corrected for interferences. The error ellipse denotes the correlated 2.standard deviation as derived from "JM" standard measurements (Table S1, ESI $\dagger$ ). The fact that all data plots on the mass-dependent fractionation curve shows that $\mathrm{Cr}$ corrections did not introduce a bias resulting from excessive ${ }^{54} \mathrm{Fe}$ corrections.

samples taken from individual subjects at different intervals varied by \pm 17 to $\pm 38 \mathrm{ppm}$ ( $2 \cdot \mathrm{SD}$ over all samples, Table S2, ESI $\dagger$ ). Plasma samples varied by \pm 0.25 to $\pm 1.2 \mathrm{ppm}(2 \cdot \mathrm{SD}$ over all samples, Table 1 and Table S3, ESI $\dagger$ ) in their iron concentrations. This means that relative variations in plasma iron concentrations were much larger than those in erythrocytes.

$\delta^{56} \mathrm{Fe}$ in erythrocytes ranges from approx. -3.1 to $-2.2 \%$ (Fig. 2), a range typical for male Caucasian adults. ${ }^{3}$ The $2 \cdot \mathrm{SD}$ value of erythrocyte samples taken at different intervals from an individual subject varied between \pm 0.06 and $\pm 0.15 \%$ (2.SD), which is in most cases indistinguishable from the analytical precision of laboratory standards (Table 1). Hence, erythrocyte Fe isotopic compositions can be regarded as uniform over the 21 days investigated (Fig. 2). In plasma samples, $\delta^{56} \mathrm{Fe}$ values ranged from approx. -3.0 to $-2.0 \%$ (Fig. 3 ). The $2 \cdot \mathrm{SD}$ value of all plasma samples from an individual subject was mostly around $\pm 0.2 \%$, but varied between \pm 0.09 and $\pm 0.49 \%$ o (2.SD, Table 1). We quantified the attainable reproducibility for plasma measurements from our inter-laboratory comparison, which provides the strongest possible quantification of the most likely source of uncertainty, i.e. mass-spectrometric bias from uncorrectable matrix effects. For our 16 duplicate measurements $\delta^{56} \mathrm{Fe}$ is on average $0.26 \%$ and $\delta^{57} \mathrm{Fe} 0.37 \%$ lower at GFZ Potsdam than at the University of Hannover (Table S3, ESI $\dagger$ ). This systematic bias resulted from the entirely different run conditions and places a lower limit on the reproducibility that is attainable for such complex matrix. Such an effect might arise, for example, from excess amounts of organic carbon that were still present in the Fe separates during MC-ICP-MS analysis. Calculating the $2 \cdot \mathrm{SD}$ value from the sixteen duplicates, we obtain for $\delta^{56} \mathrm{Fe} 0.28 \%$ and for $\delta^{57} \mathrm{Fe} 0.39 \%$. We use this 
Table 1 Mean and 2.SD of $\delta^{56 / 54} \mathrm{Fe}$ iron in blood and plasma and the difference between means in each subject

\begin{tabular}{|c|c|c|c|c|c|c|c|c|c|c|c|c|c|c|}
\hline \multirow[b]{4}{*}{ Subject } & \multicolumn{6}{|c|}{$\underline{\text { Blood samples }}$} & \multicolumn{6}{|c|}{ Plasma samples } & \multirow{2}{*}{\multicolumn{2}{|c|}{$\begin{array}{l}\begin{array}{l}\text { Difference } \\
\text { plasma }- \text { blood }\end{array} \\
0-26 \text { hours }\end{array}$}} \\
\hline & \multirow{3}{*}{$\begin{array}{l}\text { Fe conc. } \\
{[\mathrm{ppm}]}\end{array}$} & \multirow{3}{*}{$\begin{array}{l}2 \cdot \mathrm{SD} \\
{[\mathrm{ppm}]}\end{array}$} & \multicolumn{2}{|c|}{$0-490$ hours } & \multicolumn{2}{|c|}{$0-26$ hours } & \multirow{3}{*}{$\begin{array}{l}\text { Fe conc. } \\
{[\mathrm{ppm}]}\end{array}$} & \multicolumn{2}{|c|}{$0-26$ hours } & \multirow{3}{*}{$\begin{array}{l}2 \cdot \mathrm{SD} \\
{[\% 0]} \\
\end{array}$} & \multirow{3}{*}{$\begin{array}{l}\delta^{56 / 54} \mathrm{Fe} \\
{\left[\%{ }^{\circ}\right]} \\
\text { Potsdam }\end{array}$} & \multirow{3}{*}{$\begin{array}{l}2 \cdot \mathrm{SD} \\
{[\% 0]} \\
\end{array}$} & & \\
\hline & & & \multirow{2}{*}{$\begin{array}{l}\delta^{56 / 54} \mathrm{Fe} \\
{[\% 0]}\end{array}$} & \multirow{2}{*}{$\begin{array}{l}2 \cdot \mathrm{SD} \\
{[\% \circ]} \\
\end{array}$} & \multirow{2}{*}{$\begin{array}{l}\delta^{56 / 54} \mathrm{Fe} \\
{[\% \circ]}\end{array}$} & \multirow{2}{*}{$\begin{array}{l}2 \cdot \mathrm{SD} \\
{[\% \circ]} \\
\end{array}$} & & \multirow{2}{*}{$\begin{array}{l}2 \cdot \mathrm{SD} \\
{[\mathrm{ppm}]}\end{array}$} & $\begin{array}{l}\delta^{56 / 54} \mathrm{Fe} \\
{[\% 0]}\end{array}$ & & & & \multicolumn{2}{|c|}{$\delta^{56 / 54} \mathrm{Fe}[\% 0]$} \\
\hline & & & & & & & & & Hannover & & & & Hann & Pots \\
\hline 5101 & 433 & 32 & -2.214 & 0.059 & -2.194 & 0.032 & 1.01 & 0.63 & -2.31 & 0.45 & -1.95 & - & -0.12 & 0.25 \\
\hline 5102 & 428 & 22 & -2.490 & 0.075 & -2.470 & 0.019 & 0.59 & 0.25 & -2.21 & 0.20 & -2.33 & 0.13 & 0.26 & 0.15 \\
\hline 5103 & 452 & 38 & -2.627 & 0.079 & -2.609 & 0.027 & 1.21 & 1.19 & -2.30 & 0.23 & -2.40 & - & 0.31 & 0.21 \\
\hline 5104 & 471 & 19 & -2.801 & 0.090 & -2.785 & 0.095 & 0.70 & 0.48 & -2.77 & 0.15 & - & - & 0.01 & - \\
\hline 5105 & 491 & 26 & -2.708 & 0.115 & -2.730 & 0.102 & 0.77 & 0.97 & -2.45 & 0.17 & - & - & 0.28 & - \\
\hline 5106 & 460 & 17 & -2.676 & 0.059 & -2.686 & 0.028 & 0.66 & 0.36 & -2.56 & 0.10 & - & - & 0.13 & - \\
\hline 5107 & 466 & 25 & -2.626 & 0.109 & -2.648 & 0.069 & 0.92 & 0.64 & -2.38 & 0.49 & -2.58 & - & 0.26 & 0.06 \\
\hline 5108 & 443 & 26 & -2.640 & 0.151 & -2.690 & 0.048 & 0.66 & 0.31 & -2.29 & 0.23 & -2.61 & 0.11 & 0.40 & 0.08 \\
\hline 5109 & 442 & 28 & -3.061 & 0.081 & -3.070 & 0.088 & 0.71 & 0.59 & -2.73 & 0.29 & -2.95 & - & 0.34 & 0.12 \\
\hline 5110 & 495 & 28 & -2.642 & 0.112 & -2.634 & 0.112 & 1.02 & 0.48 & -2.53 & 0.25 & - & - & 0.10 & - \\
\hline 5111 & 497 & 25 & -2.904 & 0.067 & -2.910 & 0.090 & 0.71 & 0.30 & -2.58 & 0.18 & -2.88 & 0.17 & 0.33 & 0.03 \\
\hline 5112 & 495 & 28 & -2.561 & 0.075 & -2.573 & 0.069 & 0.71 & 0.35 & -2.07 & 0.09 & - & - & 0.51 & - \\
\hline Mean & 464 & & -2.663 & & -2.667 & & 0.81 & & -2.43 & & -2.53 & & 0.23 & 0.13 \\
\hline Min & 428 & 17 & -3.061 & 0.059 & -3.070 & 0.019 & 0.59 & 0.25 & -2.77 & 0.09 & -2.95 & 0.11 & -0.12 & 0.03 \\
\hline Max & 497 & 38 & -2.214 & 0.151 & -2.194 & 0.112 & 1.21 & 1.19 & -2.07 & 0.49 & -1.95 & 0.17 & 0.51 & 0.25 \\
\hline
\end{tabular}

reproducibility in the interpretation of the data. The plasma samples taken at 26 hours of subjects 5101 and 5102, respectively, yielded $\delta^{56} \mathrm{Fe}$ values that deviated more than $25 \%$ from that of all other plasma samples of these subjects (Table S3, ESI $\dagger$ ). We have no explanation for this deviation, and used instead the repeat measurement performed at GFZ Potsdam that agreed well with the other samples from these subjects. Overall, the iron isotopic composition in plasma was more variable than in erythrocytes. We attribute this variability to the lower reproducibility of these measurements.

$\delta^{56} \mathrm{Fe}$ in plasma samples is higher than that in erythrocytes in 11 out of 12 samples by 0.01 to $0.51 \%$ (Fig. 4). Only the subject 5101 features a $\delta^{56} \mathrm{Fe}$ value in its plasma sample that is lower than that in erythrocytes by $0.21 \%$. The average difference in $\delta^{56} \mathrm{Fe}$ between plasma iron and erythrocyte iron is $0.23 \%$ (Table 1). This difference is only marginally in excess of the 2.SD value resulting from our inter-laboratory comparison. We therefore cannot conclude with certainty that the difference is real. We note that after administration of $\left[{ }^{58} \mathrm{Fe}\right] \mathrm{SBR} 759,{ }^{57} \mathrm{Fe}$ in plasma samples is elevated over baseline as the ${ }^{58} \mathrm{Fe}$ spike added also contains elevated levels of ${ }^{57} \mathrm{Fe}$ (see Table S4, ESI $\dagger$ ). ${ }^{56} \mathrm{Fe}$ however is unaffected, and plots of ${ }^{56} \mathrm{Fe} /{ }^{54} \mathrm{Fe} v s .{ }^{58} \mathrm{Fe} /{ }^{54} \mathrm{Fe}$ do not yield correlations as would be expected if contamination of ${ }^{56} \mathrm{Fe}$ by $\left[{ }^{58} \mathrm{Fe}\right] \mathrm{SBR} 759$ would occur. However, plasma samples might have been affected by hemolysis. We proceed to discuss this question in comparison to literature data in the next section.

\section{Discussion}

Lysis of erythrocytes with liberation of hemoglobin (hemolysis) may occur in vitro when blood samples are taken and plasma is prepared. Hemolysis can further occur if the centrifugation procedure has failed to result in a complete separation between iron in erythrocytes and iron in plasma. Given the large concentration differences (480 ppm versus $\sim 1 \mathrm{ppm}$, respectively) minor hemolysis could contaminate plasma samples with erythrocyte isotope composition. In order to minimize hemolysis during several consecutive blood withdrawals, blood samples were collected via a plastic cannula placed in a forearm vein that remained through sampling 26 hours post last dose. Blood sampling and plasma preparation were carried out throughout the study by qualified clinical and laboratory personnel. Study-specific training on blood sampling, including the recognition and minimization of hemolysis, was also provided.

As spectrophotometric measurements of hemoglobin levels in our plasma samples were not done, we evaluate this possibility based on literature data. Our measured plasma iron concentrations are within known values that range between 0.75 and 1.75 ppm for males ${ }^{4 b, 22}$ suggesting that iron in plasma was not contaminated by erythrocyte iron. We can evaluate the contribution of iron to plasma from hemoglobin further from hemoglobin levels quantified in plasma by spectrophotometry. ${ }^{23}$ The hemoglobin levels in plasma reported in that study range between 0.002 and 0.019 (mean 0.007 ) w/V\%. Using the iron concentration of hemoglobin $(0.35$ weight $\%)$ typical iron contamination levels between 0.07 and $0.66 \mathrm{ppm}$ with a mean of $0.24 \mathrm{ppm}$ can be calculated. Since our samples have been taken and centrifuged with great care, we adopt the mean minimum hemoglobin iron contamination level of $0.24 \mathrm{ppm}$ and assume that all iron in excess of this value is truly plasma iron. This assumption means that iron concentrations of uncontaminated plasma are between 0.5 and $1.5 \mathrm{ppm}$.

To calculate the plasma iron isotope composition despite the possibility of contamination by erythrocyte hemolysis, we plotted the difference in $\delta^{56} \mathrm{Fe}$ between erythrocytes and plasma against the inverse concentration of iron in plasma (Fig. 5). In such a diagram, mixtures yield a linear relationship and the 

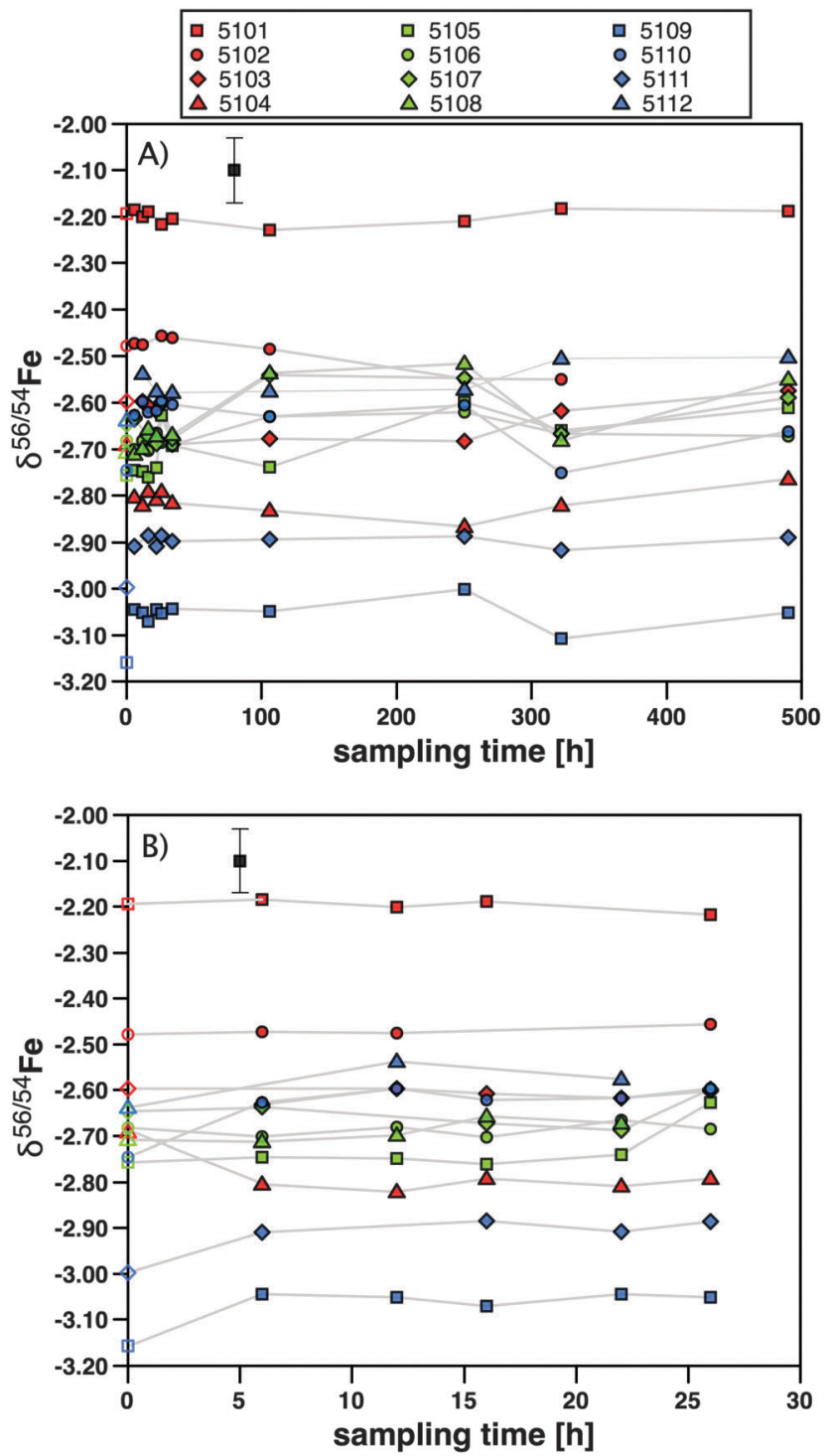

Fig. $2 \delta^{56} \mathrm{Fe}$ in erythrocytes of the 12 subjects against sampling time. (A) All data from Day 1 to Day 21. Note that $\delta^{56} \mathrm{Fe}$ in erythrocytes is invariant with time over this period. (B) The first 26 hours were sampled at higher time resolution. The symbols denote individual subjects.

end member compositions can be inferred. The figure shows that the isotope difference between Fe in erythrocytes and Fe in plasma increases with a decrease in the concentration. As $\delta^{56} \mathrm{Fe}_{\text {erythrocytes }}$ is constant for each subject this means that $\delta^{56} \mathrm{Fe}_{\text {plasma }}$ increases with a decrease in the concentration. This trend is more pronounced for samples taken from Hours 22 to 26 (open colored symbols) than those taken from Hours 0 to 16 (closed colored symbols). We explain this trend with the decreasing effect of hemolysis introduced during sampling, as the inserted plastic cannula remained in place throughout. Hence the samples taken last approach the true $\delta^{56} \mathrm{Fe}_{\text {plasma }}$ most closely.

A linear regression analysis through all our data (Fig. 5) yields a slope of -0.2 with $R^{2}$ of 0.2 . We used this slope to model where $\delta^{56} \mathrm{Fe}_{\text {erythrocytes }}-\delta^{56} \mathrm{Fe}_{\text {plasma would plot if plasma }}$

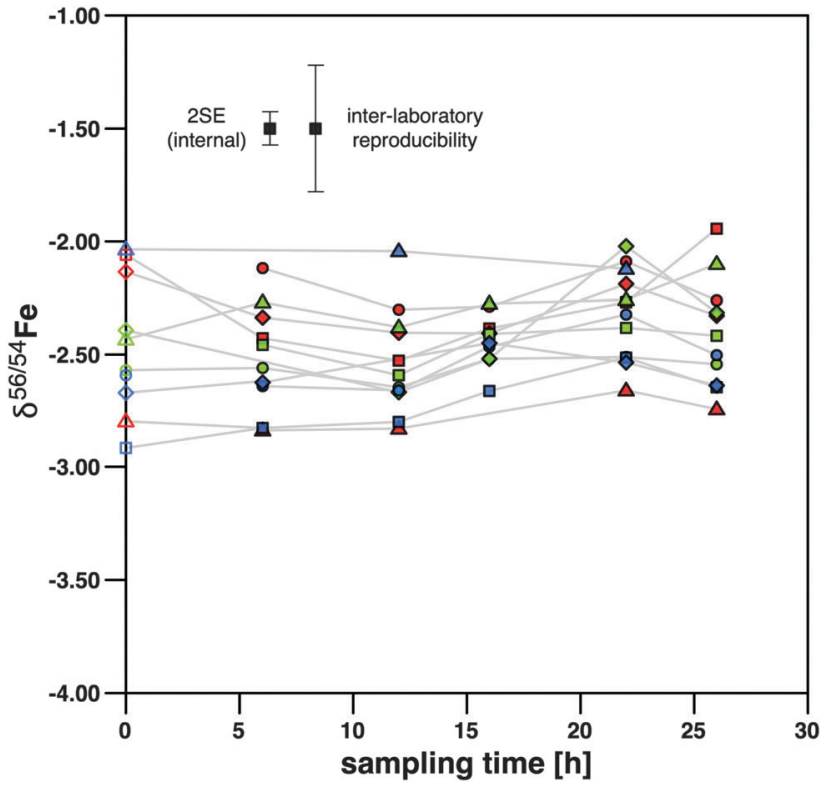

Fig. $3 \delta^{56} \mathrm{Fe}$ in plasma of the 12 subjects against sampling time. The symbols denote individual subjects and are the same as in Fig. 2. Error bars show 2 standard deviations.

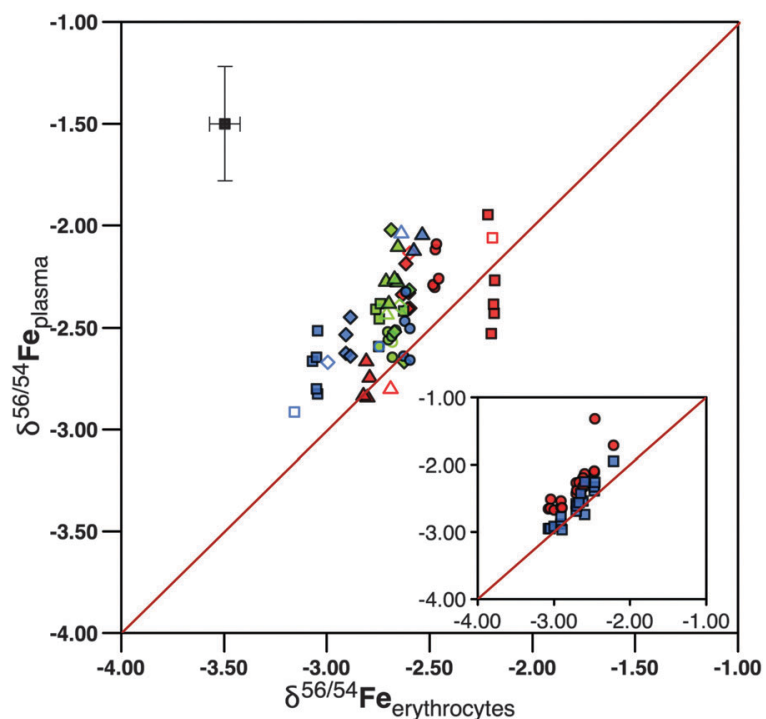

Fig. $4 \delta^{56} \mathrm{Fe}$ in plasma against erythrocytes. Most data plot within $0.5 \%$ within the $1: 1$ line, showing that the individual subjects carry a distinct iron isotope composition that is similar between erythrocytes and plasma. The symbols denote individual subjects and are the same as in Fig. 2 . The inset shows results of the inter-laboratory comparison of plasma samples. Samples measured at Hannover are shown in red and those at GFZ Potsdam in blue. The plasma samples taken at 24 hours of subjects 5101 and 5102 yielded $\delta^{56} \mathrm{Fe}$ that deviated significantly from all other plasma samples of these subjects when measured at Hannover. For these samples the Potsdam data were plotted in the main plot.

was contaminated by variable amounts of erythrocytes during centrifugation (Fig. 5). In this calculation, we assumed the "pure", but unknown plasma iron isotope composition with three independent models, as shown by the lines and tick marks in Fig. 5 - in each model the iron concentration in 


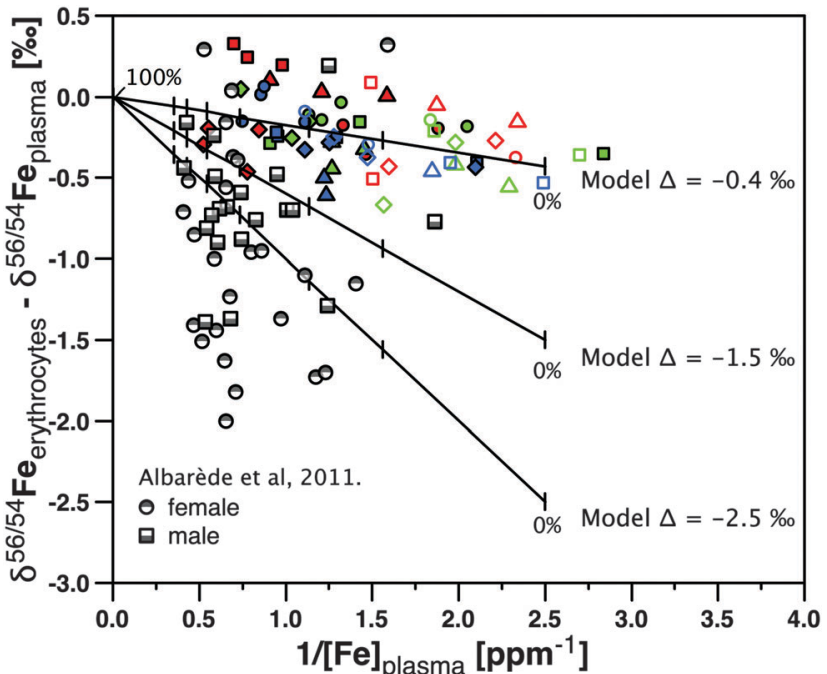

Fig. $5 \delta^{56} \mathrm{Fe}_{\text {erythrocytes }}-\delta^{56} \mathrm{Fe}_{\text {plasma }}$ versus $1 / \mathrm{Fe}$ concentration in plasma. The colored symbols are from this study (subjects as in Fig. 2), where closed symbols show data for samples taken from 0 to 16 hours and open symbols for samples taken from 22 to 26 hours. The grey symbols show data from ref. 13. The lines and tick marks show three mixing models that serve to predict how data would be aligned if plasma iron were contaminated by erythrocyte-sourced iron. In each model the iron concentration in erythrocytes was set to $480 \mathrm{ppm}$, while the iron concentration in plasma was set to $0.4 \mathrm{ppm}$. The true isotope difference $\Delta^{56} \mathrm{Fe}$ erythrocytes - plasma was set to $-0.4 \%$, $-1.5 \%$, and $-2.5 \%$ in the three models. The weight $\%$ tick marks on the model curve indicate the weight fraction of total erythrocyte sample mixed with total plasma by hemolysis (from 0 to 0.5 and 100 weight\%).

erythrocytes was set to $480 \mathrm{ppm}$, while the iron concentration in uncontaminated plasma was set to $0.4 \mathrm{ppm}$. For our data the isotope difference $\Delta^{56} \mathrm{Fe}_{\text {erythrocytes-plasma }}$ obtained to satisfy a slope of -0.2 is $-0.4 \%$. We conclude that this value is the average difference between erythrocyte Fe isotope composition and uncontaminated plasma isotope composition in our samples.

We can compare this relationship to the one obtained in ref. $13 \mathrm{Fe}$ in these serum samples ${ }^{13}$ were on average $1 \%$ heavier than erythrocytes in females and $0.6 \%$ heavier in males, respectively. We note however that while our mean Fe concentrations in plasma $(0.8 \mathrm{ppm})$ were similar to the serum data from ref. $4 b$ (0.9 ppm), Fe concentrations in serum samples of Albarède $e t a l .{ }^{13}$ were higher with a mean concentration of $1.4 \mathrm{ppm}$. If the samples in that study were still affected by hemolysis, modeled slopes demand that their $\delta^{56} \mathrm{Fe}$ in the serum differs by $-1.5 \%$ from erythrocytes in males, and by $-2.5 \%$ in females, respectively, (see $\Delta^{56} \mathrm{Fe}$ erythrocytes-plasma models $-1.5 \%$ and $-2.5 \%$ in Fig. 5). We regard such strong isotope fractionation as unlikely. If these experiments were not affected by hemolysis, the possibility remains that isotope ratios are subject to an unidentified analytical mass bias. Given the difficult matrix that plasma or serum represents, and the challenge we have encountered in developing a suitable analytical protocol, this explanation cannot be fully excluded.

Using our new plasma data presented here, we proceed with the conclusion that $\delta^{56} \mathrm{Fe}$ in plasma is at least $0.4 \%$ higher than that in erythrocytes.
Where does the isotope fractionation between plasma $\mathrm{Fe}$ and erythrocyte Fe occur? The liver, spleen, and red bone marrow contain iron that can be up to $1 \%$ o heavier than erythrocytes. ${ }^{1,5}$ Transferrin is the molecule transporting iron contained in plasma into and from these compartments. In this regard, it is important that this study recruited healthy male subjects who were iron replete i.e. nonanemic and are expected to have a normal erythrocyte turnover rate. At the end of their $\sim 120$ day lifespan, heme iron from erythrocytes in blood, and myoglobin from the damaged muscle tissue are recycled after being phagocytosed by circulating macrophages or the reticuloendothelial system (RES) of the spleen ${ }^{24}$ and released back into the plasma bound to transferrin. This recycling rate is approximately $2 \mathrm{mg}$ per day from erythrocytes and another $2 \mathrm{mg}$ from the muscle tissue, ${ }^{25}$ potentially dominating the isotope composition of the iron contained in plasma. As heavy liver iron is stored in the ferritin molecule, release of iron from ferritin could play a key role in tissue fractionation since tissues enriched in heavier iron isotopes are generally high in ferritin content. In general, two chemical reaction types, binding to organic molecules and redox processes, lead to different degrees of isotope fractionation. Fe(III) - chelate fractionation is $+0.2 \%$ at equilibrium. ${ }^{26}$ This fractionation factor is too small to explain the large difference between plasma and liver iron or erythrocyte iron. Reduction from ferric to ferrous iron through activity of a reductase is a more likely explanation. ${ }^{6,11}$ Iron binding to ferritin involves oxidation of iron via a ferroxidase. ${ }^{27}$ As noted in the Introduction, these redox processes can be accompanied by equilibrium isotope fractionation amounting to up to $3 \%$ in $\delta^{56} \mathrm{Fe},{ }^{9,10}$ potentially favouring heavy iron isotopes in ferritin. If transferrin iron remains in the ferric state, whereas heme iron carried by erythrocytes is in the ferrous state, ${ }^{1}$ then plasma iron isotope composition will be intermediate between that of erythrocyte and ferritin iron, as the liver will release preferentially heavy iron isotopes, which are then mixed with light iron isotopes from quantitative erythrocyte recycling. Hence, redox processes play the decisive role in iron isotope fractionation between compartments of the human body, regardless of whether the pathways are direct or indirect. $^{1,13}$

\section{Conclusions}

A chemical separation procedure using microwave treatment and anion exchange chromatography was developed for analysis of iron isotopes in human blood plasma by MC-ICP-MS. The isotope composition of plasma is exceedingly sensitive to hemolysis which may occur during blood sampling and subsequent centrifugation. Hence, while within analytical precision the iron isotopic ratios are identical between whole blood and plasma of 12 healthy male Caucasian adults, these results are also compatible with a plasma iron isotope composition that is at least $0.4 \%$ higher in $\delta^{56} \mathrm{Fe}$ than that of erythrocytes. Ferritin is a key player that can induce isotope fractionation by release and uptake of iron, mixing isotopically heavier iron from the liver with plasma 
while at the same time lighter iron is released from erythrocytes. Redox processes involved in ferritin binding and unbinding are the key players.

\section{Acknowledgements}

We acknowledge Ingo Horn (Leibniz Universität Hannover, Germany) for supporting mass spectrometric measurements, Ronny Schoenberg (Universität Tübingen, Germany) for advice in the design of this study, Gerrit Budde (Universität Münster, Germany) for laboratory support, and Thomas Walczyk (National University of Singapore) and an anonymous manuscript reviewer for their constructive comments.

\section{References}

1 T. Walczyk and F. von Blanckenburg, Deciphering the iron isotope message of the human body, Int. J. Mass Spectrom., 2005, 242, 117-134.

2 (a) F. Albarède and B. L. Beard, in Geochemistry of Non-Traditional Stable Isotopes, ed. C. M. Johnson, B. L. Beard and F. Albarède, Mineralogical Society of America, Blacksburg, 2004, vol. 55, pp. 113-152; (b) N. Jakubowski, T. Prohaska, F. Vanhaecke, P. H. Roos and T. Lindemann, Inductively coupled plasmaand glow discharge plasma-sector field mass spectrometry, J. Anal. At. Spectrom., 2011, 26, 727-757, DOI: 10.1039/ c0ja00007h.

3 T. Walczyk and F. von Blanckenburg, Natural iron isotope variations in human blood, Science, 2002, 295, 2065-2066.

4 (a) T. Ohno, A. Shinohara, I. Kohge, M. Chiba and T. Hirata, Isotopic analysis of Fe in human red blood cells by multiple collector-ICP-mass spectrometry, Anal. Sci., 2004, 20, 617-621; (b) L. Van Heghe, J. Delanghe, H. Van Vlierberghe and F. Vanhaecke, The relationship between the iron isotopic composition of human whole blood and iron status parameters, Metallomics, 2013, 5, 1503-1509, DOI: 10.1039/ c3mt00054k; (c) F. von Blanckenburg, J. Noordmann and M. Guelke-Stelling, The Iron Stable Isotope Fingerprint of the Human Diet, J. Agric. Food Chem., 2013, 61, 11893-11899, DOI: $10.1021 / \mathrm{jf} 402358 \mathrm{n}$.

5 K. Hotz, H. Augsburger and T. Walczyk, Isotopic signatures of iron in body tissues as a potential biomarker for iron metabolism, J. Anal. At. Spectrom., 2011, 26, 1347-1353, DOI: 10.1039/c0ja00195c.

6 V. Balter, A. Lamboux, A. Zazzo, P. Telouk, Y. Leverrier, J. Marvel, A. P. Moloney, F. J. Monahan, O. Schmidt and F. Albarède, Contrasting $\mathrm{Cu}, \mathrm{Fe}$, and $\mathrm{Zn}$ isotopic patterns in organs and body fluids of mice and sheep, with emphasis on cellular fractionation, Metallomics, 2013, 5, 1470-1482, DOI: $10.1039 / \mathrm{c} 3 \mathrm{mt} 00151 \mathrm{~b}$.

7 (a) M. W. Hentze, M. U. Muckenthaler and N. C. Andrews, Balancing acts: Molecular control of mammalian iron metabolism, Cell, 2004, 117, 285-297, DOI: 10.1016/ s0092-8674(04)00343-5; (b) W. I. Leong and B. Loennerdal, in Iron Physiology and Pathophysiology in Humans, ed.
G. J. Anderson and G. D. MacLaren, Humana Press, New York, 2012, pp. 81-99.

8 (a) N. C. Andrews and P. J. Schmidt, Iron Homeostasis, Annu. Rev. Physiol., 2007, 69, 69-85; (b) A. T. McKie and R. J. Simpson, in Iron Physiology and Pathophysiology in Humans, ed. G. J. Anderson and G. D. MacLaren, Humana Press, New York, 2012, pp. 101-116.

9 S. A. Welch, B. L. Beard, C. M. Johnson and P. S. Braterman, Kinetic and equilibrium $\mathrm{Fe}$ isotope fractionation between aqueous Fe(II) and Fe(III), Geochim. Cosmochim. Acta, 2003, 67, 4231-4250.

10 A. D. Anbar, A. A. Jarzecki and T. G. Spiro, Theoretical investigation of iron isotope fractionation between $\mathrm{Fe}\left(\mathrm{H}_{2} \mathrm{O}\right)(3+)(6)$ and $\mathrm{Fe}\left(\mathrm{H}_{2} \mathrm{O}\right)(2+)(6)$ : Implications for iron stable isotope geochemistry, Geochim. Cosmochim. Acta, 2005, 69, 825-837, DOI: 10.1016/ j.gca.2004.06.012.

11 R. M. Graham, A. C. G. Chua and D. Trinder, in Iron Physiology and Pathophysiology in Humans, ed. G. J. Anderson and G. D. MacLaren, Humana Press, New York, 2012, pp. 117-139.

12 N. D. Chasteen and P. M. Harrison, Mineralization in ferritin: an efficient means of iron storage, J. Struct. Biol., 1999, 126, 182-194.

13 F. Albarède, P. Telouk, A. Lamboux, K. Jaouen and V. Balter, Isotopic evidence of unaccounted for $\mathrm{Fe}$ and $\mathrm{Cu}$ erythropoietic pathways, Metallomics, 2011, 3, 926-933, DOI: 10.1039/ c1mt00025j.

14 H. P. Gschwind, D. G. Schmid, F. von Blanckenburg, M. Oelze, K. van Zuilen, A. Slade, S. Stitah, D. Kaufmann and P. Swart, Iron uptake and ferrokinetics in healthy male subjects of an iron-based oral phosphate binder (SBR759) labeled with the stable isotope ${ }^{58} \mathrm{Fe}$, Metallomics, DOI: 10.1039/c4mt00126e.

15 R. Schoenberg and F. von Blanckenburg, An assessment of the accuracy of stable Fe isotope ratio measurements on samples with organic and inorganic matrices by highresolution multicollector ICP-MS, Int. J. Mass Spectrom., 2005, 242, 257-272.

16 A. Stenberg, D. Malinovsky, I. Rodushkin, H. Andrén, C. Pontér, B. Öhlander and D. C. Baxter, Separation of Fe from whole blood matrix for precise isotopic ratio measurements by MC-ICP-MS: a comparison of different approaches, J. Anal. At. Spectrom., 2003, 18, 23-28.

17 N. Dauphas, A. Pourmand and F. Z. Teng, Routine isotopic analysis of iron by HR-MC-ICPMS: How precise and how accurate?, Chem. Geol., 2009, 267, 175-184, DOI: 10.1016/ j.chemgeo.2008.12.011.

$18 \mathrm{~S}$. Weyer and J. Schwieters, High precision Fe isotope measurements with high mass resolution MC-ICPMS, Int. J. Mass Spectrom., 2003, 226, 355-368.

19 P. D. P. Taylor, R. Maeck and P. DeBievre, Determination of the absolute isotopic composition and atomic-weight of a reference sample of natural iron, Int. J. Mass Spectrom. Ion Processes, 1992, 121, 111-115, https://irmm.jrc.ec.europa. eu/refmat_pdf/IRMM-014_cert.pdf.

20 K. Moeller, R. Schoenberg, T. Grenne, I. H. Thorseth, K. Drost and R. B. Pedersen, Comparison of iron isotope 
variations in modern and Ordovician siliceous Fe oxyhydroxide deposits, Geochim. Cosmochim. Acta, 2014, 126, 422-440.

21 A. D. Anbar, J. E. Roe, J. Barling and K. H. Nealson, Nonbiological fractionation of iron isotopes, Science, 2000, 288, 126-128.

22 C. Lentner, Geigy Scientific Tables, Ciba-Geigy Corporation Ciba-Geigy Limited, Basle, Switzerland: West Caldwell, New Jersey, USA, 8th edn, 1984, vol. 3, pp. 84-85.

23 B. Copeland, P. Dyer and A. Pesce, Hemoglobin determination in plasma or serum by first-derivative recording spectrophotometry. Evaluation of the procedure of Soloni, Cunningham, and Amazon, Am. J. Clin. Pathol., 1989, 92, 619.

24 G. M. Brittenham, in Iron Metabolism in Health and Disease, ed. J. H. Brock, J. W. Halliday, M. J. Pippard and
L. W. Powell, W.B. Saunders Company Ltd., London, 1994, pp. 31-62.

25 T. H. Bothwell, Absorption of iron, Annu. Rev. Med., 1970, 21, 145-156.

26 (a) K. Dideriksen, J. A. Baker and S. L. S. Stipp, Equilibrium Fe isotope fractionation between inorganic aqueous $\mathrm{Fe}(\mathrm{III})$ and the siderophore complex, Fe(III)-desferrioxamine B (vol 269, p. 280, 2008), Earth Planet. Sci. Lett., 2008, 272, 758, DOI: 10.1016/j.epsl.2008.06.001; (b) J. L. L. Morgan, L. E. Wasylenki, J. Nuester and A. D. Anbar, Fe Isotope Fractionation during Equilibration of Fe-Organic Complexes, Environ. Sci. Technol., 2010, 44, 6095-6101, DOI: 10.1021/es100906z.

27 G. R. Bakker and R. F. Boyer, Iron incorporation into apoferritin. The role of apoferritin as a ferroxidase, J. Biol. Chem., 1986, 261, 13182-13186. 